\title{
Transmigrasi Wilayah Perbatasan di Indonesia
}

\author{
Sukmaniar $^{1}$, Wahyu Saputra ${ }^{2}$ \\ ${ }^{12}$ FKIP Universitas PGRI Palembang \\ Email : milanisti_wahyu@yahoo.com
}

(Received: Agustus 2019; Reviewed: Agustus 2019; Accepted: September 2019; Published: September 2019)

Ini adalah artikel dengan akses terbuka dibawah license CC BY-NC-4.0 (C2019 oleh penulis (https://creativecommons.org/licenses/by-nc/4.0/ ).

\begin{abstract}
This literature review aims to examine transmigration at the Indonesian border. The research uses a literature review approach derived from research journals, scientific posters, and proceedings from seminars relating to transmigration at the Indonesian border. The results of this study can be explained that the transmigration program in Indonesia's border regions has both positive and negative impacts. Transmigration is able to contribute to the development of natural resources at the border with the skills of transmigrants so that natural resources can be utilized by border residents. The negative impact of the transmigration program is that it occurs to indigenous people who feel they are not getting enough change in their economies so that social gaps arise between indigenous people and transmigrants. Indigenous people feel that the results of their land management are not as good as those of transmigrants, resulting in inequality in income disparities that present conflict between the two.
\end{abstract}

Keywords: Transmigration, Border Area

\begin{abstract}
ABSTRAK
Kajian literatur ini bertujuan untuk mengkaji tentang transmigrasi di perbatasan Indonesia. Pada penelitian menggunakan pendekatan kajian literatur yang berasal dari jurnal-jurnal hasil penelitian, poster-poster ilmiah, dan prosiding dari seminar yang berkaitan tentang tranmigrasi yang ada di perbatasan Indonesia. Hasil dari studi ini dapat dijelaskan bahwa program transmigrasi di wilayah perbatasan Indonesia mempunyai dampak positif maupun dampak negatif. Transmigrasi mampu memberikan kontribusi dalam pengembangan sumber daya alam yang berada di perbatasan dengan keterampilan para transmigran sehingga sumber daya alam dapat dimanfaatkan oleh penduduk perbatasan. Dampak negatif dari program transmigrasi yaitu terjadi pada penduduk asli yang merasakan kurang mendapatkan perubahan pada perekonomiannya sehingga muncul kesenjangan sosial antara penduduk asli dengan para transmigran. Penduduk asli merasa hasil pengelolaan lahannya tidak sebaik dengan transmigran sehingga terjadi ketimpangan perbedaan pendapatan yang menghadirkan konflik diantara keduanya.
\end{abstract}

Kata Kunci: Transmigrasi, Wilayah Perbatasan 


\section{PENDAHULUAN}

Indonesia yang merupakan wilayah kepulauan menyebabkan persebaran penduduk yang tidak merata pada setiap wilayahnya. Berdasarkan data dari BPS (2017) jumlah penduduk Indonesia adalah 258.705.000 jiwa. Angka tersebut merupakan jumlah yang cukup besar. Pada data dari Population Reference Bureau (2017) menyatakan bahwa Indonesia masih menduduki posisi ke-empat penduduk terbesar di dunia setelah Cina, India, dan Amerika Serikat. Indonesia memiliki karakteristik topografi yang unik seperti pegunungan yang tersebar di berbagai pulau-pulau. Topografi pegunungan dan kelautan ini menyebabkan sulit dan biaya yang tidak sedikit dalam mengakses dan menjamah satu tempat ke tempat lainya. Menurut Badan Pusat Statistik bahwa letak astronomis Indonesia yaitu $6^{\circ} 04^{\prime}$ $30^{\prime \prime}$ Lintang Utara dan $11^{\circ} 00^{\prime} 36^{\prime \prime}$ Lintang Selatan dan $94^{\circ} 58^{\prime} 21^{\prime \prime}$ sampai $141^{\circ} 01^{\prime} 10^{\prime \prime}$ Bujur Timur. Hal inilah menyebabkan kepadatan penduduk di Indonesia berbedabeda secara signifikan. Adapun data kepadatan penduduk pada tahun 2016 yang tidak merata di negara Indonesia dapat dijelaskan melalui tabel berikut ini:

Tabel 1. Jumlah Penduduk dan Kepadatan Penduduk Menurut Provinsi di Indonesia Tahun 2016

\begin{tabular}{|l|l|r|r|}
\hline No. & \multicolumn{1}{|c|}{ Provinsi } & Penduduk (ribu) & Kepadatan Penduduk per km ${ }^{2}$ \\
\hline 1. & Aceh & $14.096,2$ & 88 \\
\hline 2. & Sumatera Utara & $5.259,5$ & 193 \\
\hline 3. & Sumatera Barat & $6.501,0$ & 125 \\
\hline 4. & Riau & $3.458,9$ & 75 \\
\hline 5. & Jambi & $8.160,9$ & 69 \\
\hline 6. & Sumatera Selatan & $1.904,8$ & 89 \\
\hline 7. & Bengkulu & $8.205,1$ & 96 \\
\hline 8. & Lampung & $1.401,8$ & 237 \\
\hline 9. & Kepulauan Bangka Belitung & $2.028,2$ & 85 \\
\hline 10. & Kepulauan Riau & $10.277,6$ & 247 \\
\hline 11. & DKI Jakarta & $47.379,4$ & 15.478 \\
\hline 12. & Jawa Barat & $34.019,1$ & 1.339 \\
\hline 13. & Jawa Tengah & $3.720,9$ & 1.037 \\
\hline 14. & DI Yogyakarta & $39.075,3$ & 1.188 \\
\hline 15. & Jawa Timur & $12.203,1$ & 817 \\
\hline 16. & Banten & $4.200,1$ & 1.263 \\
\hline 17. & Bali & $4.896,2$ & 727 \\
\hline 18. & Nusa Tenggara Barat & $5.203,5$ & 264 \\
\hline 19. & Nusa Tenggara Timur & $4.861,7$ & 107 \\
\hline 20. & Kalimantan Barat & $2.550,2$ & 33 \\
\hline 21. & Kalimantan Tengah & $4.055,5$ & 17 \\
\hline 22. & Kalimantan Selatan & $3.501,2$ & 105 \\
\hline 23. & Kalimantan Timur & 666,3 & 27 \\
\hline 24. & Kalimantan Utara & $2.436,9$ & 9 \\
\hline 25. & Sulawesi Utara & $2.921,7$ & 176 \\
\hline 26. & Sulawesi Tengah & $8.606,4$ & 47 \\
\hline 27. & Sulawesi Selatan & $2.551,0$ & 184 \\
\hline 28. & Sulawesi Tenggara & $1.150,8$ & 67 \\
\hline 29. & Gorontalo & $1.306,5$ & 102 \\
\hline 30. & Sulawesi Barat & $1.715,5$ & 78 \\
\hline 31. & Maluku & $1.185,9$ & 37 \\
\hline 32. & Maluku Utara & 893,4 & 37 \\
\hline 33. & Papua Barat & $3.207,4$ & 10 \\
\hline 34. & Papua & & \\
\hline & & & \\
\hline
\end{tabular}




\begin{tabular}{|c|c|c|r|}
\hline No. & \multicolumn{1}{|c|}{ Provinsi } & Penduduk (ribu) & Kepadatan Penduduk per $\mathbf{k m}^{\mathbf{2}}$ \\
\hline & Indonesia & $\mathbf{2 5 8 . 7 0 5 . 0 0 0}$ & $\mathbf{1 3 5}$ \\
\hline
\end{tabular}

Sumber: BPS, Statistik Indonesia 2016

Tabel di atas secara jelas memaparkan bahwa persebaran penduduk tidak merata. Pada provinsi-provinsi yang rendah kepadatan penduduknya ada berada di wilayah Kalimatan Timur, Kalimantan Utara, Papua Barat, dan Papua. Perlu diketahui bahwa sebagian provinsi-provinsi tersebut merupakan wilayah perbatasan yang ada di Indonesia. Pada Provinsi Kalimantan Timur, Papua Barat, dan Papua merupakan wilayah berbatasan yang menjadi ujung tombak Negara Kesatuan Republik Indonesia (NKRI). Minimumnya penduduk yang tinggal di wilayah perbatasan disebabkan karena banyak faktor-faktor penting yang semestinya menjadi pusat perhatian pemerintah.

Salah satu upaya agar pemerataan persebaran penduduk sehingga dapat mengoptimalkan sumber daya yang tersedia adalah dengan cara meneruskan kegiatan transmigrasi. Hal tersebut didukung oleh Dinas Tenaga Kerja Transmigrasi dan Kependudukan Provinsi Jawa Timur (2016) menyatakan bahwa transmigrasi merupakan alternatif dari permasalahan kependudukan seperti pengendalian jumlah penduduk, kepadatan penduduk serta mengurangi peningkatan laju pertumbuhan penduduk yang tinggi di negara Indonesia. Yuminarti (2017) menambahkan bahwa transmigrasi dapat dijadikan kesempatan untuk memperbaiki taraf kehidupan yang lebih baik lagi dari kehidupan sebelumnya. Transmigrasi juga merupakan bentuk cara kebijakan publik untuk mengalokasikan penduduk yang telah padat penduduknya seperti penduduk yang ada di Pulau Jawa menuju ke wilayah perbatasan yang terpencil dan tertinggal.

Menurut Prihatin (2012) menyatakan bahwa negara kita dengan $81.900 \mathrm{~km}$ garis pantai dan berbatasan pada negara-negara dengan jumlah 10 negara ini masih belum mendapatkan pemerataan pembangunan dengan optimal terutama ketertinggalan pada bidang ekonomi dan sosial. Pemerintah perlu memahami bahwa memindahkan penduduk yang telah terbiasa tinggal di wilayah perkotaan menuju ke wilayah perbatasan bukan salah satu upaya yang mudah untuk dilakukan. Perlu dirumuskan prinsip-prinsip yang mendasar agar penduduk tersebut bersedia dan mendapatkan kenyamanan secara sandang, pangan dan papan. Namun, pada kajian literatur perlu diketahui karakteritikkarakteristik wilayah-wilayah perbatasan yang telah mengalami ketertinggalan dan dapat diupayakan menjadi wilayah transmigrasi yang optimal sehingga persebaran penduduk yang merata telah mampu direalisasikan.

\section{METODE}

Tulisan ini menggunakan metode kajian literatur dari jurnal-jurnal penelitian, artikel-artikel ilmiah terkait dengan pembahasan kajian transmigrasi di wilayah perbatasan Indonesia. Penulis juga menelaah kajian literatur yang berasal poster-poster, prosiding dari seminar-seminar ilmiah yang pada umumnya masih berkaitan tentang tema transmigrasi. Pengkajian dimulai dari menelaah data publikasi statistik dari Badan Pusat Statistik dan jurnal-jurnal yang relevan. Konsep dan teori yang berhubungan dengan tema pada tulisan ini terus digali dan dianalisis dalam mencapai kesimpulan. Menurut Levy dan Ellis (2006) menyatakan bahwa landasan teoritis yang kuat sangat diperlukan dalam berkontribusi untuk pembenaran pada sebuah metodologi yang akan digunakan serta memberikan justifikasi pendekatan yang sesuai dan tepat pada studi mereka. Menurut Marshall (2015) menjelaskan bahwa kedalaman dan keluasan topik yang dipilih dapat digabungkan sehingga mampu menghasilkan sebuah kajian literatur yang baik dan jelas.

\section{HASIL DAN PEMBAHASAN}

\section{Hasil}

Perpindahan penduduk dari satu wilayah asal menuju ke wilayah tujuan dengan harapan mendapatkan perubahan hidup yang lebih baik merupakan konsep dari migrasi. Pada data berikut ini jumlah migrasi masuk seumur hidup menurut provinsi di 
Indonesia tahun 2016 dapat dirincikan melalui tabel berikut ini:

Tabel 2. Jumlah Migrasi Masuk Seumur Hidup Menurut Provinsi di Indonesia Tahun 2016

\begin{tabular}{|c|c|c|c|c|c|c|}
\hline No. & Provinsi & 1980 & 1990 & 2000 & 2010 & 2015 \\
\hline 1. & Aceh & 146.307 & 194.709 & 100.166 & 213.553 & 209.815 \\
\hline 2. & Sumatera Utara & 570.863 & 459.652 & 447.897 & 521.847 & 519.843 \\
\hline 3. & Sumatera Barat & 134.712 & 217.796 & 245.000 & 344.254 & 358.123 \\
\hline 4. & Riau & 356.272 & 689.036 & 1.534 .849 & 1.911 .760 & 1.881 .079 \\
\hline 5. & Jambi & 298.366 & 473.434 & 566.153 & 738.961 & 710.428 \\
\hline 6. & Sumatera Selatan & 617.745 & 936.817 & 987.157 & 1017.990 & 966.060 \\
\hline 7. & Bengkulu & 122.785 & 251.621 & 355.048 & 347.651 & 337.041 \\
\hline 8. & Lampung & 1.793 .053 & 1.730 .903 & 1.485 .218 & 1.463 .929 & 1.362 .387 \\
\hline 9. & $\begin{array}{l}\text { Kepulauan } \\
\text { Belitung }\end{array}$ & - & - & 94.334 & 206.705 & 192.729 \\
\hline 10. & Kepulauan Riau & - & - & - & 801.073 & 881.035 \\
\hline 11. & DKI Jakarta & 2.599 .367 & 3.170 .215 & 3.541 .972 & 4.007 .515 & 3.647 .328 \\
\hline 12. & Jawa Barat & 1.003 .758 & 2.408 .626 & 3.271 .882 & 5.225 .271 & 4.961 .541 \\
\hline 13. & Jawa Tengah & 350.724 & 516.315 & 708.308 & 902.711 & 1.015 .615 \\
\hline 14. & DI Yogyakarta & 180.367 & 266.500 & 385.117 & 562.384 & 571.948 \\
\hline 15. & Jawa Timur & 465.949 & 575.541 & 781.590 & 925.510 & 924.152 \\
\hline 16. & Banten & & - & 1.758 .408 & 2.766 .750 & 2.491 .589 \\
\hline 17. & Bali & 65.271 & 124.919 & 221.722 & 406.921 & 428.511 \\
\hline 18. & Nusa Tenggara Barat & 56.081 & 69.466 & 107.605 & 115.832 & 121.828 \\
\hline 19. & $\begin{array}{ll}\text { Nusa } & \text { Tenggara } \\
\text { Timur } & \\
\end{array}$ & 42.614 & 48.159 & 106.053 & 185.083 & 176.608 \\
\hline 20. & Kalimantan Barat & 112.244 & 199.829 & 269.722 & 293.229 & 293.992 \\
\hline 21. & Kalimantan Tengah & 142.257 & 241.192 & 423.014 & 526.737 & 527.473 \\
\hline 22. & Kalimantan Selatan & 145.417 & 274.745 & 360.324 & 487.245 & 509.967 \\
\hline 23. & Kalimantan Timur & 296.963 & 604.549 & 856.251 & 1.308 .485 & 1.120 .017 \\
\hline 24. & Kalimantan Utara & - & - & - & - & 189.396 \\
\hline 25. & Sulawesi Utara & 91.460 & 89.096 & 147.091 & 206.139 & 188.136 \\
\hline 26. & Sulawesi Tengah & 187.024 & 287.447 & 369.634 & 452.792 & 465.614 \\
\hline 27. & Sulawesi Selatan & 118.984 & 225.279 & 273.875 & 364.288 & 346.168 \\
\hline 28. & Sulawesi Tenggara & 106.027 & 237.602 & 366.817 & 447.484 & 443.602 \\
\hline 29. & Gorontalo & - & - & 26.888 & 64.585 & 64.448 \\
\hline 30. & Sulawesi Barat & - & - & - & 172.113 & 175.283 \\
\hline 31. & Maluku & 130.109 & 186.735 & 75.640 & 123.165 & 134.500 \\
\hline 32. & Maluku Utara & - & - & 60.834 & 107.681 & 106.920 \\
\hline 33. & Papua Barat & - & - & - & 250.196 & 272.151 \\
\hline 34. & Papua & 96.079 & 262.873 & 332.015 & 435.773 & 491.656 \\
\hline & Indonesia & & & & & \\
\hline
\end{tabular}

Sumber : BPS, Statistik Indonesia 2016

Migrasi memiliki beberapa jenis, salah satunya yaitu transmigrasi. Transmigrasi sering dilakukan oleh pemerintah untuk mendistribusikan penduduknya ke segala penjuru wilayahnya. Pada tabel di atas dapat dilihat bahwa para migran menempati wilayah Pulau Jawa seperti DKI Jakarta, Jawa Barat, Jawa Tengah, dan Banten. Namun terdapat wilayah-wilayah lain seperti Riau, Lampung, dan Kalimantan Timur.
Penjelasan di atas dapat diketahui bahwa tidak semua wilayah yang banyak pemigran yang masuk berada di wilayah perbatasan dan terpencil. Hal ini bisa dianalisis angka migran yang masuk seumur hidup dan menetap di wilayah perbatasan dan terpencil masih sedikit. Papua barat contohnya hanya mencapai angka 272.151 jiwa migran yang masuk untuk menetap seumur hidup disana. 
Para migran lebih menyukai tinggal di wilayah perkotaan yang telah tersedia sarana dan prasarana kehidupan yang memadai. Tinjauan ini perlu diatasi dengan pemerataan pembangunan kota ke seluruh wilayah Indonesia khususnya bagian pedalaman dan perbatasan. Infrastruktur jalan, pendidikan, kesehatan, kegiatan ekonomi seperti pasar, dan tempat hiburan juga perlu diperhatikan agar menjadi daya tarik tersendiri dan memberikan kenyamanan pada penduduk untuk bertransmigrasi ke wilayah perbatasan. Persebaran desa yang masih tertinggal dan sangat tertinggal dapat diuraikan melalui tabel 3 berikut ini:

Tabel 3. Jumlah Desa Tertinggal Berdasarkan Wilayah Pulau di Indonesia Tahun 2015.

\begin{tabular}{|l|l|l|l|l|l|l|}
\hline No. & Wilayah Pulau & $\begin{array}{l}\text { Jumlah } \\
\text { Desa }\end{array}$ & $\begin{array}{l}\text { Jumlah } \\
\text { Desa } \\
\text { tertinggal }\end{array}$ & $\%$ & $\begin{array}{l}\text { Jumlah } \\
\text { Desa } \\
\text { Sangat } \\
\text { Tertinggal }\end{array}$ & $\%$ \\
\hline 1. & Sumatera & 22.056 & 12.482 & $56,59 \%$ & 8.241 & $37,36 \%$ \\
\hline 2. & Jawa & 22.458 & 15.087 & $67,18 \%$ & 806 & $3,59 \%$ \\
\hline 3. & Kalimantan & 6.382 & 3.063 & $47,99 \%$ & 1.702 & $26,67 \%$ \\
\hline 4. & Sulawesia & 8.233 & 4.398 & $53,42 \%$ & 1.213 & $14,73 \%$ \\
\hline 5. & $\begin{array}{l}\text { Nusa Tenggar } \\
\text { \& Bali }\end{array}$ & 3.599 & 2.277 & $63,27 \%$ & 424 & $11,78 \%$ \\
\hline 6. & Maluku & 1.958 & 782 & $39,94 \%$ & 833 & $42,54 \%$ \\
\hline 7. & Papua & $\mathbf{5 . 2 0 4}$ & $\mathbf{1 . 0 0 2}$ & $\mathbf{1 9 , 2 5 \%}$ & $\mathbf{4 . 0 4 9}$ & $\mathbf{7 7 , 8 1 \%}$ \\
\hline & $\begin{array}{l}\text { Total } \\
\text { Kabupaten/Kota }\end{array}$ & 74.045 & 39.091 & $\mathbf{5 2 , 7 9 \%}$ & 17.268 & $23,32 \%$ \\
\hline
\end{tabular}

Sumber: Kementerian Desa, Pembangunan Daerah Tertinggal, dan Transmigrasi Republik Indonesia. Rakornas Kementerian KOMINFO:2015

Tabel 3 secara signifikan dijelaskan bahwa Pulau Papua mencapai angka tertinggi dengan kondisi desa yang sangat tertinggal. Papua merupakan wilayah perbatasan Indonesia yang jarang dihuni oleh penduduk Indonesia. Banyak aspek yang mempengaruhi mengapa fenomena sosial ini bisa terjadi di wilayah ini. Penyebab dari terjadi gelombang tertinggalnya wilayah pedesaan di Papua yaitu karena kurangnya sarana dan prasarana kehidupan. Akses yang sulit dijangkau dari satu tempat ke tempat lain juga mempengaruhi seseorang untuk berpikir panjang tinggal di wilayah tersebut. Selayaknya Pulau Papua mendapatkan perhatian khusus dari pemerintah untuk lebih ditingkatkan lagi pembangunan desa. Faktor budaya yang tidak dapat terlepas dari permasalahan ini. Kekhasan dan keaslian suku di Papua yang unik belum tentu bisa membuat transmigran mampu melakukan penyesuaian dan beradaptasi dengan baik.

Unsur masalah yang sangat mendasar bagi para praktisi dan pemangku kebijakan lainnya untuk dapat diselesaikan dengan mudah sehingga dari waktu ke waktu hal ini menjadi masalah klasik yang telah terulang dari dahulu kala. Yumiarta (2017) mengatakan bahwa berdasarkan hasil kajiannya bahwa penduduk asli Papua itu sendiri belum bisa mendapatkan keuntungan dari program transmigrasi yang telah diberlakukan. Penduduk asli Papua yang telah bersedia memberikan lahannya kepada para transmigran masih merasa bahwa manfaat yang mereka peroleh belum terlihat atau belum optimal. Mereka merasa perkembangan kemampuannya dalam bercocok tanam masih tidak mengalami kemajuan. Penduduk asli masih merasa nyaman dengan kebiasaannya dalam mencari makanan dengan berburu kemudian meramu makanan yang telah tersedia di alamnya.

Manay (2016) memaparkan bahwa transmigrasi dilakukan dalam kegiatan perpindahan penduduk dengan harapan dapat memberikan efek pada perekonomian rakyat. Prihatin (2012) juga menambahkan bahwa 
penduduk asli mengalami kesenjangan sosial karena belum mampu mengikuti dan mendapatkan manfaat dari program transmigrasi sehingga penghasilan mereka di wilayah perbatasan cenderung lebih sedikit dibandingkan warga transmigran.

Paradigma penduduk di wilayah perbatasan sangat berharap dengan adanya program transmigran dapat memberikan faedah yang besar pada desa di perbatasannya yang terpencil dan mampu mandiri mengembangkan wilayahnya sendiri seperti pada UU Desa pasal 3 pada Koordinasi Pemberdayaan Masyarakat Pemberdayaan Masyarakat, Desa, dan Kawasan Kementerian Koordinator Bidang Pembangunan Manusia dan Kebudayaan Republik Indonesia (2016) yang menjelaskan bahwa ada asas dalam mengatur desa yaitu rekognisi, subsiduaritas, keberagaman, kebersamaan, ke gotongroyongan, kekeluargaan, musyawarah, demokrasi, kemandirian, partisipasi, kesetaraan, pemberdayaan, dan keberlanjutan.

Penduduk asli juga mengharapkan dengan adanya pembangunan desa sebaiknya bertujuan untuk membuat manusia dapat mendapatkan kehidupan yang sejahtera dan mengurangi kemiskinan.

Kemiskinan yang terjadi di wilayah perbatasan disebabkan karena salah satu faktornya yaitu kurangnya optimalisasinya sumber daya alam yang tersedia. Kita dapat mengetahui bahwa sumber daya alam yang ada di wilayah Indonesia memiliki kekayaan yang sangat besar. Namun, kurangnya optimalisasi oleh penduduknya sehingga kekayaan yang telah tersimpan di bumi pertiwi Indonesia dieksplor lebih optimal oleh perusahaan asing sehingga penduduk kurang dapat merasakannya.

Kelemahan pada sumber daya manusia merupakan masalah klasik yang sering muncul negara ini. Persebaran sumber daya manusia hanya tersebar di wilayahwilayah tertentu saja seperti wilayah-wilayah yang pada penduduknya. Transmigrasi ini dapat menjadi jembatan antara pemerataan sumber daya manusia untuk mengelola sumber daya alam di seluruh penjuru wilayah Indonesia khususnya di wilayah perbatasan.

Kementerian Desa, Pembangunan Daerah tertinggal, dan Transmigrasi Republik Indonesia (2015) mendeskripsikan bahwa dasar pada strategi pembangunan nasional dapat disebutkan bahwa setiap pembangunan harus berjalan baik tanpa terjadinya ketimpangan disetiap wilayahnya. Kesejahteraan kehidupan rakyat untuk lebih ditingkatkan dengan memanfaatkan sumber daya alam yang telah tersedia di Indonesia khususnya dalam konteks ini tentang pengelolaan di wilayah perbatasan.

Pembangunan di desa bagian pinggiran juga harus tetap dilakukan, perekonomian harus ke arah pada macammacam usaha dan sektor yang mencakup pada tenaga kerja penduduk yang baik dan berkualitas, memiliki inovasi yang tinggi, tingkat kreatifitas yang baik serta selalu menggunakan teknologi yang tinggi dan tepat guna, sehingga dapat ditarik secara garis besar bahwa pembangunan nasional berasal dari daerah-daerah yang mempunyai tingkat pembangunan yang baik dan berkualitas.

\section{Perkembangan Transmigrasi di Daerah Perbatasan Indonesia}

Penelitian-penelitian mengenai transmigrasi, daerah perbatasan maupun transmigrasi di daerah perbatasan telah dilakukan di Indonesia, sejak zaman orde baru, reformasi hingga desentralisasi. Berdasarkan kajian yang ditemukan, menurut Goos (1992) Transmigrasi yang telah dilakukan di Maluku menjadi keuntungan bagi daerah tersebut karena dengan adanya program transmigrasi, Maluku mendapatkan investasi modal dari berbagai pihak serta mendapatkan pembangunan infrastruktur untuk menunjang kemajuan di daerah tersebut.

Hal tersebut menunjukkan bahwa program transmigrasi menjadi sebuah keuntungan bagi daerah yang menjadi tujuan, dengan adanya transmigrasi kemajuan ekonomi dapat berkembang dengan pesat karena terdapat investasi yang dilakukan penduduk, selain itu juga sarana dan prasarana seperti pendidikan, kesehatan dan sebagainya akan semakin berkembang dengan adanya program transmigrasi. Berikutnya, hasil yang berbeda yang ditemukan oleh Fearnside mengenai transmigrasi merupakan program yang dapat merusak lingkungan karena para transmigran merusak hutan. 
Menurut Fearnside

(1997)

Transmigrasi yang dilakukan di Indonesia telah menjadi penyebab rusaknya lingkungan yang ada khususnya hutan di Indonesia, walaupun yang terjadi adalah pengurangan tekanan penduduk di Jawa, namun hilangnya hutan dari program transmigrasi menjadi pelajaran yang sangat berarti bagi negaranegara yang berada di wilayah tropis agar hutan tidak hilang seperti yang terjadi di Indonesia.

Dari pendapat tersebut, terlihat bahwa selain memiliki dampak positif dari program transmigrasi yaitu dengan mengurangi jumlah penduduk yang padat disuatu daerah ke daerah yang tidak padat penduduk, transmigrasi juga memiliki dampak negatif yaitu rusaknya hutan di Indonesia yang disebabkan oleh transmigran yang melakukan penebangan pohon pada hutan didaerah tujuan mereka melakukan transmigrasi.

Hasil penelitian lain mengenai daerah perbatasan dari Potter yang menyatakan bahwa daerah perbatasan perlu dilakukan pengawasan dengan cara menanam kelapa sawit disepanjang perbatasan. Menurut Potter (2009) sumber daya alam yang ada pada daerah perbatasan antara Indonesia dengan Malaysia yang berada di Kalimantan, oleh pemerintah Indonesia telah dilakukan penanaman kelapa sawit disepanjang perbatasan sebagai batas yang dapat dikontrol didaerah perbatasan oleh pemerintah, hal tersebut dilakukan karena sering terjadinya penyelundupan dan pembalakan liar di daerah tersebut.

Berdasarkan pendapat Potter, daerah perbatasan yang rentan akan terjadinya tindakan illegal oleh negara lain, seperti di Kalimantan antara negara Indonesia dengan Malaysia dapat diantisipasi dengan cara menanami kelapa sawit supaya dapat diawasi dengan baik oleh pemerintah sehingga tidak akan terjadi lagi tindakan illegal yang merugikan negara Indonesia.

Hasil penelitian yang juga dilakukan oleh Potter (2012) yang menyatakan bahwa terdapat cara pandang baru dalam program transmigrasi di Indonesia khususnya di Kalimantan yaitu dengan cara membuka lahan kelapa sawit yang dalam dekade terakhir telah tumbuh dengan pesat, hal tersebut dilakukan dengan tujuan untuk menarik para transmigran dari Jawa, Bali, Nusa Tenggara Timur dan Nusa Tenggara Barat untuk melakukan Transmigrasi yang nantinya akan menciptakan Kota Mandiri Terpadu dengan perkebunan kelapa sawit sebagai daya tariknya.

Pendapat tersebut menunjukkan bahwa dengan dibukanya lahan kelapa sawit mampu menjadi daya tarik terbaru bagi calon transmigran untuk melakukan transmigrasi dari daerah dengan tingkat kepadatan penduduk yang tinggi ke tingkat kepadatan penduduk yang rendah, hal tersebut dilaksanakan agar terciptanya pertumbuhan kota yang baru secara mandiri dan terpadu. Dari hasil-hasil penelitian di atas, terlihat bahwa terdapat perkembangan mengenai kondisi program Transmigrasi dan Daerah Perbatasan yang merupakan dinamika program Transmigrasi yang dilakukan oleh Pemerintah Indonesia.

Pada hasil penelitiannya Suriadi dkk (2010) menjelaskan yaitu ketika melihat dari aspek pembangunan jalan lintas di Papua Merauke sampai Waropko dapat dianalisis jalinan hubungan sosial penduduk asli dengan penduduk asli lainnya dapat terhubung dengan baik, tidak hanya sekedar penduduk asli saja. Hubungan dengan para pendatang yang dapat dirincikan seperti para pedagang, transmigran, dan pegawai yang masuk ke wilayah menjadi lebih mudak untuk diakses.

Pada Direktorat Daerah Tertinggal, Transmigrasi, dan Perdesaan (2016) memaparkan pada wilayah perbatasan di Pulai Papua memiliki kebutuhan pembangunan dengan karakteristik wilayah masing-masing. Pada wilayah Keerom dibutuhkannya pengelolaan sawit, tanaman coklat dan ternak. Berbeda dengan wilayah perbatasan di Raja Ampat memiliki kebutuhan pembudidayaan sumber daya alam bahari seperti lobster, ikan kerapi, teripang, penyu, dan lain-lain sehingga diharapakan dengan adanya transmigran yang ahli dalam bidan tersebut mampu mengembangkan sumber daya alam bahari yang ada di wilayah tersebut.

\section{Kesenjangan di Daerah Perbatasan}

Transmigran yang tinggal di perbatasan tentunya mendapatkan masalahmasalah yang mesti mereka hadapi. Ketidakserasian antara pendatang dan 
penduduk asli terkadang menjadi faktor penghambat mereka untuk berkeinginan melakukan kegiatan transmigrasi. Menurut Budianta (2010) mengidentifikasi permasalahan yang muncul di wilayah perbatasan yaitu pertama, terletak pada kebijakan yang sulit untuk dilakukan. Kedua, daerah perbatasan selalu mengalami keterlambatan dalam pembangunan. Ketiga, Kecenderungan wilayah satu dengan wilayah lainnya karena berada pada daerah perbatasaan. Ketidakcocokan pembangunan dan beda persepsi pada kegiatan program pembangunan baik yang dilakukan oleh penduduk maupun dengan pemerintah.

Dwiyanto Dkk (2003) menambahkan bahwa program transmigrasi sering menghadapi kesenjangan dan masalah yang dilatarbelakangi oleh beberapa penyebab seperti terdapatnya kesalahpahaman penduduk asli dengan para transmigran yang datang, masalah yang berkaitan tentang politik antar pejabat, dan yang begitu nampak tentang masalah perekonomian, kepemilikan tanah dan perebutan sumber daya alam. Nitiyasa (2013) juga menitik beratkan pada masalah kesenjangan ekonomi. Permasalahan ekonomi antara warga asli dengan transmigran sehingga terjadi kesalahpahaman dan belum mampu menemukan kata sepakat diantaranya. Etnis pun sering dikait-kaitkan tentang ketidakcocokan diantara keduanya.

Berdasarkan hasil penelitian dari Yuminarti (2017) memaparkan bahwa legalitas lahan harus dijadikan landasan penting para transmigran yang ada di perbatasan Papua. Pada legalitas ini diharapkan keamanan dan kenyaman transmigran untuk menghindari konflik dengan penduduk asli di wilayah perbatasan. Kesenjangan terjadi karena memang hadir dalam keadaan situasi yang kurang menguntungkan bagi penduduk asli. Program yang diharapkan dapat menyebarkan pengetahuan pertanian misalnya sehingga mampu mengembangkan hasil panen dan meningkatkan ekonominya justru terjadi terbalik. Transmigran lebih cenderung mampu menguasai medan perkebunan lebih baik dan dominan. Kebiasaan lama yang sulit diubah membuat keadaan lebih memburuk sehingga program transmigran di perbatasan tidak bisa berjalan dengan baik sebagaimana mestinya.
Revitalisasi program transmigrasi yang telah dijelaskan oleh Prihatin (2012) perlu dilakukan demi mengatasi kesalahankesalahan yang terjadi di wilayah-wilayah perbatasan. Paradigma baru tentang optimalisasi instansi-intansi yang terkait, meningkatkan suasana usaha yang kondusif dan transparansi dalam teknis di lapangan yang dijelaskan secara rinci dan spesifik pada sistem organisasi, pegantian kerugian masyarakat setempat, pengadaan lahan untuk perekonomian maupun permukiman yang diharapka menuju arah untuk kepentingan umum.

\section{SIMPULAN DAN SARAN Simpulan}

Program transmigrasi dapat dijadikan solusi untuk pemerataan pesebaran penduduk yang ada di Indonesia khususnya untuk wilayah perbatasan Indonesia yang kepadatan penduduknya masih rendah seperti beberapa contoh wilayah perbatasan yang ada di Pulau Maluku, Kalimantan dan Papua. Program transmigrasi juga dapat menjadi salah satu upaya untuk pengoptimalisasian sumber daya alam yang ada di wilayah perbatasan yang sangat berpotensi untuk digali dengan tujuan kesejahteraan kehidupan penduduk Indonesia yang berada di perbatasan.

Konflik yang selama ini muncul disebabkan karena ada penduduk asli merasa kurang merasakan manfaat dari program transmigrasi karena budaya asli yang masih melekat dan sulitnya menerima perubahan demi menjada tradisi maupun dalam hal rendahnya perekonomian yang didapatkan penduduk asli ketimpang dengan para transmigran. Hal ini sering kali menjadi hal yang mendasar terjadi konflik diantara keduanya.

Transmigrasi diharapkan mampu mengembangkan pembangunan dari segala aspek terutama di wilayah perbatasan, namun perlu dipahami tentang kesenjangan antara penduduk asli dan para transmigran untuk mampu bersaing secara sehat dan bekerja sama dalam kelompok masyarakat kesatuan yang utuh sehingga terjalin keharmonisan antara penduduk asli dan para transmigran.

\section{Rekomendasi}


Kajian studi ini mampu memberikan rekomendasi secara teoritis dan praktis yang dapat dijelaskan sebagai berikut:

\section{Rekomendasi Teoritis}

Kajian studi ini selanjutnya direkomendasikan untuk mengkaji lebih mendalam tentang sumber daya alam yang berpotensi untuk digali dengan kesesuaian program transmigran sehingga program tersebut dapat berjalan secara optimal dan karakteristik para transmigran serta penduduk asli yang dapat menghindarkan konflik diantara keduanya.

\section{Rekomendasi Praktis}

Kepada praktisi dan pemangku kepentingan Transmigrasi di wilayah perbatasan dapat memberikan solusi seperti mengatur dan mengontrol program transmigrasi agar dapat dirasakan oleh semua penduduk Indonesia yang tinggal di wilayah perbatasan.

Pembangunan di wilayah perbatasan dengan program transmigrasi dapat lebih optimal dengan dilakukan pelatihan dengan penduduk asli, mengkoordinir para transmigran untuk bekerja tim dalam suatu usaha pemngelolaan sumber daya alam. Pemerataan tugas dan fungsi serta hasil pendapatan yang seimbang dengan pengawasan dan managemen yang baik dan solid.

Keharmonisan antara penduduk asli dan transmigran akan terus terjalin dengan baik jika program ini dapat dilaksanakan dengan baik, adil, saling gotong royong dan merata pada setiap aspeknya.

\section{DAFTAR RUJUKAN}

Badan Pusat Statistik. 2017. Statistik Indonesia 2017. Jakarta: Badan Pusat Statistik.

Budianta, Aziz. 2010. Pengembangan Wilayah Perbatasan sebagai Upaya Pemerataan Pembangunan Wilayah di Indonesia. Jurnal SMARTek: Vol.8 No.1 Februari 2010.

Dinas Tenaga Kerja Transmigrasi dan Kependudukan Provinsi Jawa Timur. Laporan Kinerja (LKj). Surabaya: Dinas Tenaga Kerja Transmigrasi dan Kependudukan Provinsi Jawa Timur
Direktorat Daerah Tertinggal, Transmigrasi dan Perdesaan. Kajian Pengembangan Kebijakan Asimetris dalam Pembangunan di Kawasan Perbatasan Negara. Jakarta: Direktorat Daerah Tertinggal, Transmigrasi dan Perdesaan

Dwiyanto, Agus Dkk. 2003. Reformasi Tata Pemerintahan dan Otonomi Daerah. Yogyakarta: Pusat Studi Kependudukan dan Kebijakan Universitas Gadjah Mada.

Fearnside, P.M. 1997. Transmigration in Indonesia: Lessons from its environmental and social impacts. Environmental Management 21(4): 553-570

Goss Jon D. 1992. 'Transmigration in Maluku: Notes on present condition and future prospects', Cakalele: Maluku Research 3: 95

Kementerian Desa, Pembangunan Daerah Tertinggal, dan Transmigrasi Republik Indonesia. 2015. Program Pengembangan Desa dan Daerah Tertinggal Tahun 2015-2019: Target dan Lokasi Prioritas". Jakarta: Rakornas Kementerian KOMINFO. 8 Juni 2015

Koordinasi Pemberdayaan Masyarakat, Desa, dan Kawasan Kementerian Koordinator Bidang Pembangunan Manusia dan Kebudayaan Republik Indonesia. 2016. Buku Bantu Pengelolaan Pembangunan Desa. Jakarta: Koordinasi Pemberdayaan Masyarakat, Desa, dan Kawasan Kementerian Koordinator Bidang Pembangunan Manusia dan Kebudayaan Republik Indonesia . Edisi Desember 2016.

Levy, Yair. Dkk. 2006. A Systems Approach to Conduct an Effective Literature Reviews in Support of Information Systems Research. Informing Science Journal: Vol.9 Tahun 2006.

Manay. Helman. 2016. Proyek Demografi dalam Bayang-Bayang Disintegrasi Nasional Studi tentang Transmigrasi di Gorontalo, 1950-1960. Jurnal Sejarah Citra Lekha: Vol.1 No.2 Tahun 2016.

Marshall G. Writing... a Literature Review. Synergy: Imaging \& Therapy Practice: 19 Desember 2015. 
Nitiyasa, I Gde dan I Ketut Sudibia. 2013. Menggalakkan Program Transmigrasi melalui Peningkatan Pembangunan Daerah. Jurnal Piramida: Vol. IX No.1: 50-56 Tahun 2013.

Population Reference Bereau. 2017. Population Data Sheet 2017. Washington DC: Population Reference Bereau.

Potter, L. 2009. Resource periphery, corridor, heartland: Contesting land use in the Kalimantan/Malaysia borderlands. Asia Pacific Viewpoint, 50: 88-106.

Potter, L. 2012. New transmigration 'paradigm' in Indonesia: Examples from Kalimantan. Asia Pac Viewp, 53: 272-287.

Prihatin, Rohani Budi. 2012. Revitalisasi Program Transmigrasi. Aspirasi: Vol.4 No.1 Juni 2013.

Suriadi, Andi. Dkk. 2010. Peran Infrasrtuktur Jalan terhadap Dinamika Sosial dan Ekonomi di Kawasan Perbatasan Indonesia-Papua New Guinea. Jurnal Sosek Pekerjaan Umum: Vol.2 No.1 April 2010.

Yuminarti, Umi. 2017. Kebijakan Transmigrasi dalam Kerangka Otonomi Khusus di Papua: Masalah dan Harapan. Jurnal Kependudukan Indonesia: Vol 12 No.1 Juni 2017.

\section{Editor In Chief}

\section{Rosmini Maru}

rosminimaru@unm.ac.id

\section{Publisher}

Geography Education, Postgraduate

Program, Universitas Negeri Makassar

$\mathrm{Jl}$. Bonto Langkasa Gunungsari Baru

Makassar, 90222 Kampus PPs UNM

Makassar Gedung AB ruang 01, Indonesia

Email : ugj@unm.ac.id

Info Berlangganan Jurnal

085299874629 / Ihsan 